\title{
Tantangan dan Problematika Profesi Akuntan di Era Kompetitif Bagi Generasi Z
}

\author{
Ade Maya Saraswati*1, Arif Widodo Nugroho \\ 1,2,Fakultas Ekonomi dan Bisnis,Universitas Muhammadiyah Prof.DR.HAMKA \\ *e-mail: Ademaya.saraswati@uhamka.ac.id ${ }^{1}$
}

\begin{abstract}
Community service under Research Institutions and Community Services of Muhammadiyah University Prof. DR. HAMKA is an activity that integrates Tri Dharma Education into a package of community service programs implemented through an empowerment approach. This PKM activity is addressed to the students of Muhammadiyah Senior High School 4 Depok by using a Zoom application with the understanding that artificial intelligence can eliminate accounting profession. The solution provided by the proposal team based on the discussion with the principal is by providing training and understanding that artificial intelligence is not an obstacle to start the profession as an accountant. We hope that this PKM activity can increase the knowledge and understanding of artificial intelligence in relation to the impact on the accounting profession for Generation $Z$ to our partners.
\end{abstract}

Keywords: Accounting profession, artificial intelligence, challenges and problems.

\begin{abstract}
Abstrak
Pengabdian kepada masyarakat di bawah lembaga LPPM Universitas Muhammadiyah Prof. DR. HAMKA merupakan kegiatan yang mengintegrasikan Tri Dharma Pendidikan ke dalam satu paket program pengabdian masyarakatyang dilaksanakan melalui pendekatan pemberdayaan. Kegiatan PKM ini ditujukan kepada Siswa-siswi SMA Muhammadiyah 4 Depok dengan menggunakan aplikasi Zoom yang memiliki pemahaman bahwa kecerdasan buatan dapat menghilangkan profesi akuntansi. Solusi yang diberikan oleh tim pengusul berdasarkan diskusi dengan kepala sekolah adalah memberikan pelatihan dan pemahaman bahwa kecerdasan buatan bukan menjadi penghalang untuk memulai profesi sebagai akuntan. Kami berharap dengan adanya kegiatan PKM ini, mitra kami bertambah pengetahuan dan pemahaman akan kecerdasan buatan yang berdampak pada profesi akuntan bagi Generasi Z.
\end{abstract}

Kata kunci: Profesi Akuntansi, kecerdasan buatan, tantangan dan problematika.

\section{PENDAHULUAN}

Perkembangan teknologi dan informasi pada saat ini makin berkembang dengan semakin cepat dan mengharuskan adanya perubahan dalam berbagai aspek kerja untuk hampir semua bidang profesi dan pekerjaan agar semua pekerjaan dapat diselesaikan dengan cepat, tepat dan efesien. Dengan adanya teknologi diharapkan dapat membantu masyarakat dalam melakukan berbagai kegiatan sehari-harinya (Barovih \& Sugara, 2020). Demikian pula, pada bidang pengetahuan akuntansi, dimana ilmu ini merupakan salah satu cabang ilmu ekonomi yang berfokus pada hal-hal seperti analisis keuangan. Bidang ini juga dituntut untuk bisa melakukan adaptasi terhadap perkembangan teknologi informasi yang terjadi. Hal itu terbukti adanya Artificial intelligence (AI) yang marak diperbincangkan dalam akuntansi (Triatmaja et al., 2019)

Artificial intelligence (AI) adalah salah satu bidang ilmu yang mempelajari konsep-konsep mutahir untuk melakukan kalkulasi secara cerdas (Singh \& Sukhvinder, 2010). Berbagai kalkulasi yang dilaksanakan dengan menerapkan AI dilakukan untuk menghasilkan sistem komputerisasi yang aman, mudah, efektif dan efesien bagi user, dan juga membantu untuk menganalisis suatu masalah yang perlu dicari penyelesaiannya. Tetapi, pada dasarnya masih banyak pro dan kontra didalam pengimplementasian AI dalam bidang akuntansi karena informasi yang masih belum memadai.

Era Revolusi Industri 4.0 dengan kemunculan konsep data besar (big data) dan kecerdasan buatan (artificial intelligence) merupakan suatu isu dan tantangan yang harus dipecahkan dimassa yang akan datang oleh para teoris akuntansi. Maka dari itu para lulusan 
bidang akuntansi harus dapat beradaptasi terhadap semua modifikasi dan alterasi yang terjadi dengan sangat cepat ini. Hal ini disebabkan karena adanya kemungkinan peranan para lulusan akuntansi dapat digantikan oleh mesin dan dilakukan secara otomatis. (Bond, 2020).

Profesi akuntansi diperkirakan akan mengalami gangguan karena teknologi yang terus berkembang, khususnya AI atau Artificial Intelligence dan juga mesin pembelajaran (machine learning). Pada masa yang akan datang, mungkin sekitar 20 sampai dengan 30 tahun berikutnya peranan seorang akuntan yang biasa dilakukan dapat digantikan oleh mesin dan robot. Tetapi, walaupun demikian, masih banyak kelebihan yang dimiliki oleh manusia dibandingkan dengan robot dan mesin. Manusia mempunyai kemampuan dan keahlian natural yang dimiliki sejak lahir, sisi naluriah, kemampuan berpikir dan logika masih mampu mengungguli mesin dan robot. Manusia mempunyai panca indra yang berfungsi sebagai alat untuk melihat, mendengar, merasakan, menyentuh dan selanjutnya mengambil tindakan yang sesuai dengan apa yang dirasakan atau diketahuinnya dan seringkali secara spontan (Barclays, 2018).

Pada banyak bidang pekerjaan, perkembangan teknologi yang sangat pesat, seperti penggunaan komputer, laptop, media sosial, internet dan teknologi komunikasi lainnya telah membuat peranan manusia semakin berkurang. Sebagaimana dilansir di berbagai laman seperti Forbes, USA Today, Money, the Guardian, Business Insider, World Economic Forum (WEF), bahwa perkembangan teknologi telah menimbulkan berbagai perubahan yang signifikan pada dunia industri secara global. (Wijayana, 2018).

Meskipun banyak sekali kemajuan yang besar dalam berbagai fasilitas dan akses pada pendidikan, namun beberapa hal masih membutuhkan perhatian dan perbaikan yang cukup serius diantaranya kualitas dan relevansi dari pembelajaran yang diberikan kepada peserta didik. Diperlukan suatu pengkajian yang lebih detail terhadap kebijakan pendidikan dan tenaga kerja agar kinerja kerja yang dihasilkan para pendidik menjadi lebih maksimal dan lebih relevan untuk pasar yang fluktuatif. (Marzal, 2019). Menyikapi hal tersebut maka perlu untuk melakukan perubahan yang sistematis dalam pendidikan dan pelatihan.

Tim Pengabdian Kepada Masyarakat melakukan diskusi awal dengan guru dan kepala sekolah SMA 4 Muhammadiyah Depok, terkait kebutuhan apa yang diperlukan untuk pengembangan diri siswa-siswi SMA 4 Muhammadiyah Depok yang mana tergolong dalam Generasi Z. Menurut Kementrian Pemberdayaan Perempuan dan Perlindungan Anak (KemenPPPA) generasi $Z$ adalah generasi yang lahir dari 2001-2010(Budiati et al., 2018).

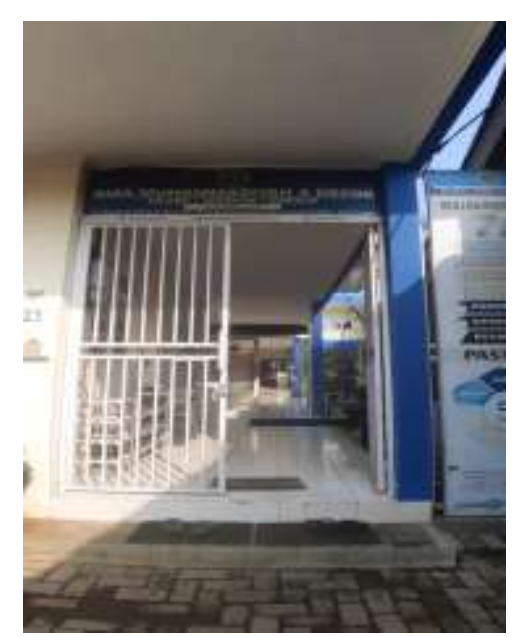

Gambar 1. Kondisi SMA Muhammadiyah 4 Depok

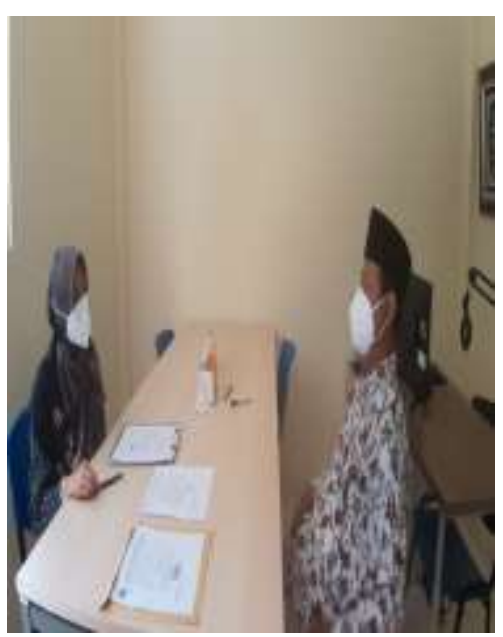

Gambar 2. Diskusi Terkait Kebutuhan Materi Mahasiswa

Guru-guru SMA 4 Muhammadiyah Depok menjelaskan bahwa siswa-siswa saat ini pesimis untuk menjadi seorang akuntan dikarenakan siswa-siswi berpikir peran akuntan akan digantikan oleh mesin. Hal tersebut juga dikonfirmasi langsung oleh beberapa siswa-siswi yang 
mengatakan bahwa demotivasi untuk melanjutkan studi ke perguruan tinggi dengan program studi akuntansi. Hal ini juga diperkuat berdasarkan jawaban sejumlah $65 \%$ peserta setuju bahawa profesi akuntan dimasa depan akan menurun karena perkembangan teknologi, 35\% tidak setuju dan sisanya $5 \%$ ragu-ragu.

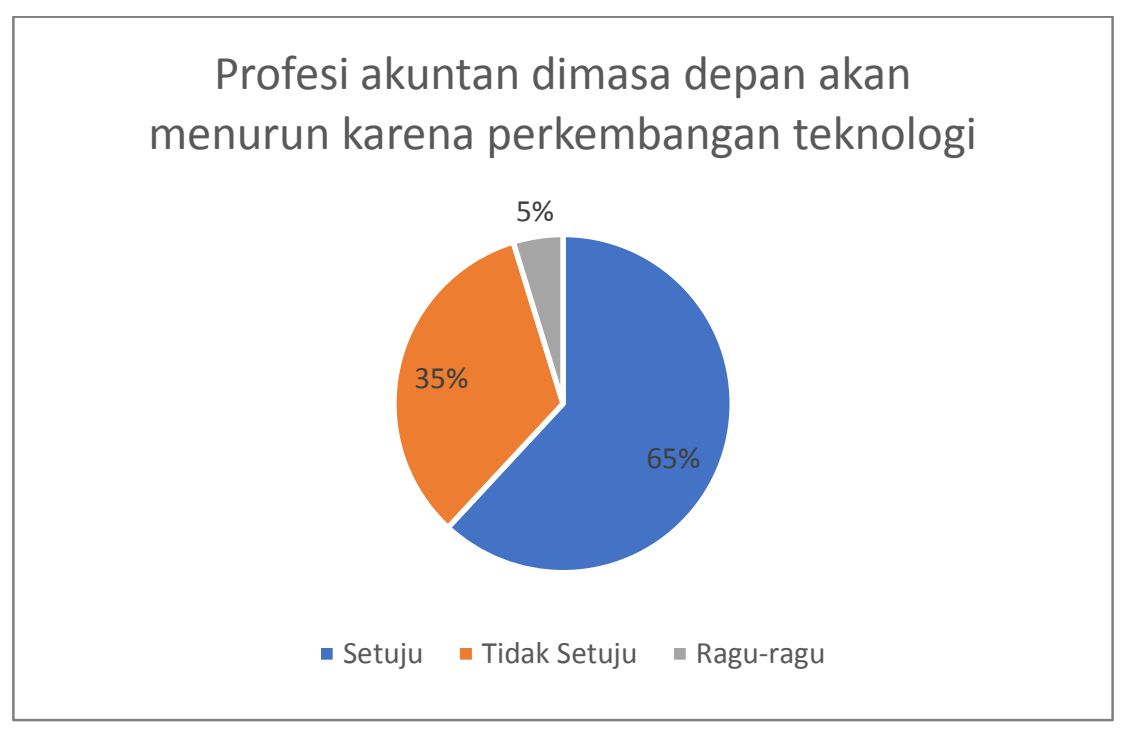

Gambar 3. Hasil Survei Pendapat

Hal ini tentu berdampak pada kesungguhan dalam proses kegiatan belajar mengajar dan dalam jangka panjang akan berdampak pada rendahnya jumlah akuntan muda di Indonesia. Berdasarkan hal tersebut, sehingga perlu ada pemahaman yang dapat meluruskan pemikiran siswa-siswi terkait dengan kecerdasan buatan (artificial intelligence) yang berkaitan dengan profesi akuntan.

\section{METODE}

Dalam analisis situasi kegiatan pengabdian kepada masyarakat ini membutuhkan pendalaman materi terkait kecerdasan buatan sehingga semua umur terutama kalangan muda mampu menambah wawasannya terkait profesi akuntansi dimasa depan Serta menyadarkan peserta bahwa seorang akuntan ataupun auditing harus mempersiapkan diri dengan mengasah baik softskill baik maupun intrapersonal skill serta mampu beradaptasi dengan perubahaan yang terjadi. Dengan demikian Artificial Intelligent tidak dipandang sebagai suatu ancaman namun sebagai suatu potensi yang dapat mendorong kinerja akuntan agar menjadi lebih baik kedepannya.

Metode kegiatan yang diterapkan untuk pengabdian masyarakat ini yaitu metode partisipatif artinya mitra binaan berpartisipasi secara aktif dalam semua tahapan kegiatan pengabdian masyakat, diantaranya sebagai berikut:

1. Sosialisasi Program

Sosialisasi program dilaksanakan setelah tahap persiapan selesai yaitu dengan melakukan pertemuan dengan mitra dan mensosialisasikan tentang program yang akan dilaksanakan.

2. Penyampaian Materi

Siswa kelas X, XI dan XII serta pendidik akan diberikan materi oleh narasumber menggunakan Ms. Power Point (PPt) terkait dengan tantangan dan problematika profesi akuntansi menghadapi kecerdasan buatan merubahnya menjadi peluang. 
3. Tanya jawab dan Diskusi

Peserta melakukan tanya jawab dan diskusi atas materi yang disampaikan. Pada tahap ini, peserta diberikan kebebasan untuk berdiskusi tentang peran akuntan dimasa depan, kecerdasan buatan, profesi akuntan dsbnya.

\section{4. $\quad$ Monitoring dan evaluasi (monev)}

Tim pelaksana melakukan monev apakah PkM yang telah dilakukan berhasil dilaksanakan oleh siswa-siswi secara berkelanjutan atau tidak. Tingkat keberhasilan webinar ini dilakukan melalui kuesioner untuk melihat apakah terjadi peningkatan pemahaman atas kecerdasan buatan yang berdampak pada profesi akuntan dan peningkatan motivasi untuk melanjutkan studi ke perguruan tinggi dengan jurusan akuntansi.

Program pelaksanaan kegiatan yaitu satu hari dan berikut ini rencana pelaksanaan kegiatan:

1. Hari pelaksanaan : 15 Juli 2021

2. Mitra Kegiatan : Siswa-siswi kelas X, XI, XII SMA 4 Muhammadiyah Depok

Rencana pelaksanaan kegiatan yaitu terdiri dari beberapa kegiatan. Kegiatan diawali dengan pendaftaran peserta melalui link google form yang disediakan, dilanjutkan dengan acara pembuka yaitu sambutan dari pihak sekolah, dilanjutkan dengan acara inti yaitu pemberian materi dan sesi tanya jawab. Terakhir, acara penutup.

\section{HASIL DAN PEMBAHASAN}

Berdasarkan hasil survei yang telah dilakukan kepada peserta webinar SMA Muhammadiyah 4 Depok dapat dilihat pada Gambar 4 sebelum webinar hanya 35\% peserta yang tertarik melanjutkan studi perguruan tinggi dengan jurusan akuntansi, 65\% peserta tidak tertarik. Setelah webinar terjadi peningkatan, terdapat $78 \%$ peserta yang tertarik dan sisanya $22 \%$ tidak tertarik.

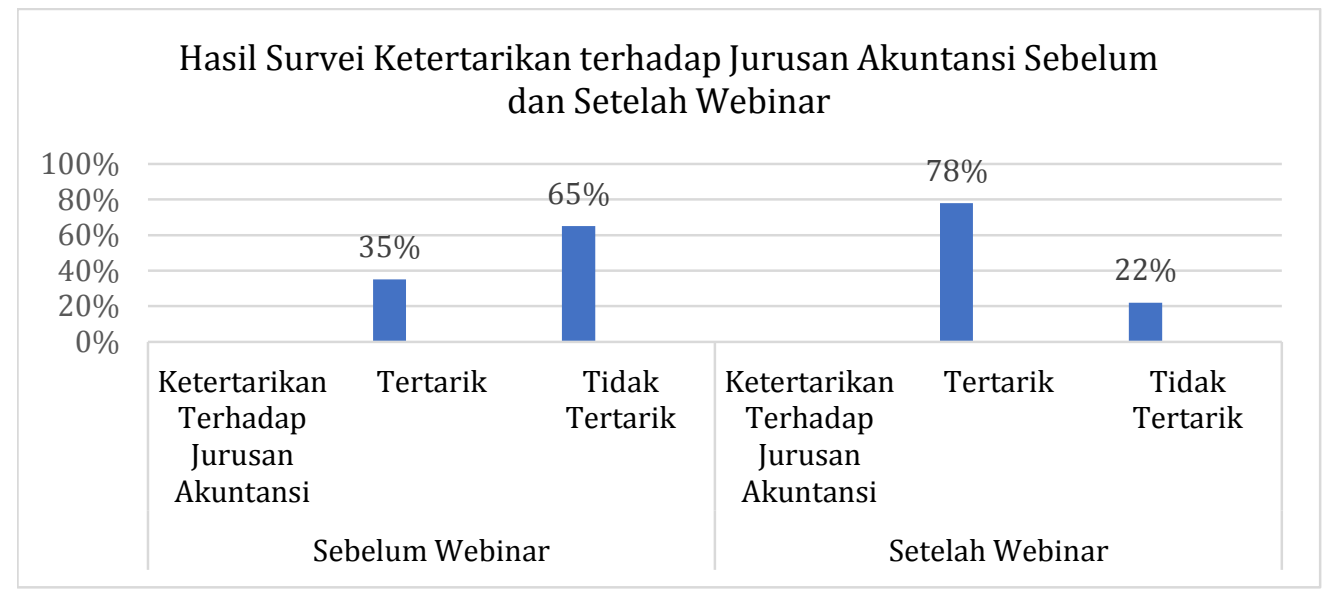

Gambar 4. Hasil Survei Ketertarikan terhadap Jurusan Akuntansi

Selain itu, setelah webinar berdasarkan hasil survei yang tersaji pada Gambar 5 terdapat perubahan pendapat akan pernyataan "Profesi akuntan dimasa depan akan menurun karena perkembangan teknologi", terdapat $20 \%$ peserta yang setuju, dan sisanya $80 \%$ tidak setuju. Dengan jawaban Hal ini berarti kegiatan webinar yang telah dilaksanakan sangat membantu peserta webinar dalam meningkatkan motivasi untuk melanjutkan studi perguruan tinggi dengan jurusan akuntansi. 


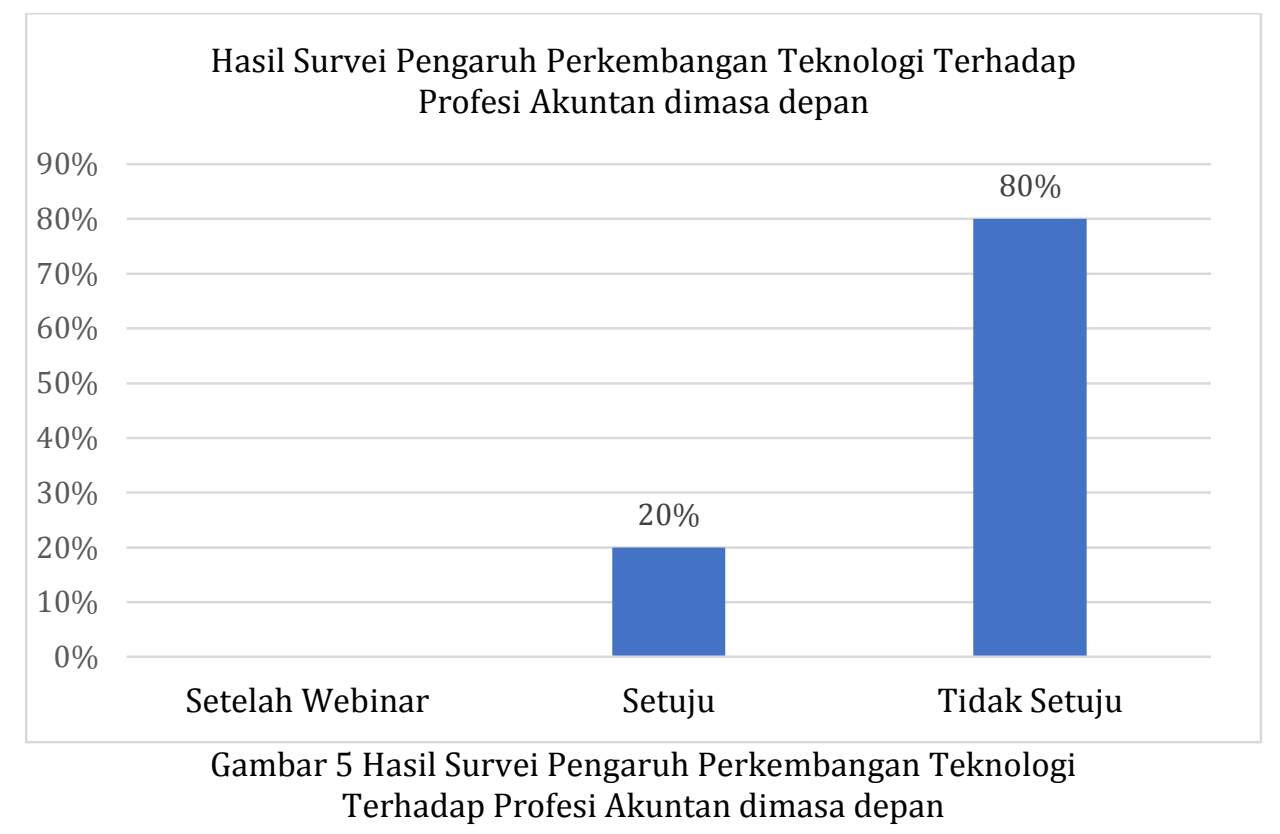

\section{KESIMPULAN}

Program pengabdian kepada masyarakat ini sangat bermanfaat bagi mitra yaitu sekolah SMA Muhammadiyah 4 Depok. Pelaksanaan kegiatan pengabdian secara kualitatif dapat dinilai telah berjalan dengan sangat baik dan sesuai target capaian yaitu meningkatkan motivasi peserta untuk melanjutkan studi dengan jurusan akuntansi serta menyadarkan peserta bahwa Profesi akuntan dimasa depan tidak akan terdistrupsi perkembangan teknologi serta menyampaikan bahwa Akuntan merupakan profesi strategis yang memerlukan long range vision tidak hanya andal dengan data dari masa lampau namun juga memiliki pandangan jauh ke depan (Putra, 2019). Dan pekerjaan akuntan beralih dari hanya judgement dan discretionary dan profesi akuntan harus meningkatkan keahliannya. Sejalan dengan pertumbuhan dan persingan bisnis global maka dibutuhkan kemampuan seorang akuntan yang lebih baik lagi (Manyika, 2017; WEF, 2018).

\section{UCAPAN TERIMA KASIH}

Kegiatan Pengabdian Kepada Masyarakat (PKM) ini adalah kerjasama antara Fakultas Ekonomi dan Bisnis Universitas Muhammadiya Prof. DR. HAMKA dengan SMA Muhammadiyah 4 Depok. Tim PKM mengucapkan terima kasih kepada kepala sekolah dan guru-guru di lingkungan SMA Muhammadiyah 4 Depok, Rektor Universitas Muhammadiyah Prof. DR. HAMKA, Dekan Fakultas Ekonomi dan Bisnis Universitas Muhammadiyah Prof. DR. HAMKA, Lembaga Pengembangan dan Pemberdayaan Masyarakat Universitas Muhammadiyah Prof. DR. HAMKA

\section{DAFTAR PUSTAKA}

Barclays. (2018). Will robots take our jobs? Impact Series. https://www.investmentbank.barclays.com/content/dam/barclaysmicrosites/ibpublic/doc uments/our-insights/Robots-at-the-gate/Barclays-IB_Will-Robots-Take-OurJobs_Infographic-1.6MB.pdf.

Barovih, G., \& Sugara, E. P. A. (2020). Pemanfaatan Aplikasi Sebagai Media Bantu Edukasi Agama Islam Untuk Anak Usia Dini. Dinamisia: Jurnal Pengabdian Kepada Masyarakat, 4(1), 152-160. Bond. (2020, November 17). Ilmu Akuntansi, Akankah Tergantikan Kecerdasan Buatan dan Mahadata? Satuan Pengawas Internal Universitas Diponegoro. 
https://spi.undip.ac.id/2020/11/17/ilmu-akuntansi-akankah-tergantikan-kecerdasanbuatan-dan-mahadata/

Budiati, I., Susianto, Y., Adi, W. P., Ayuni, S., Reagan, H. A., Larasaty, P., Setiyawati, N., Pratiwi, A. I., \& Saputri, V. G. (2018). Profil Generasi Milenial Indonesia. Kementerian Pemberdayaan Perempuan Dan Perlindungan Anak, 1-153. www.freepik.com

Manyika, J. (2017). A future that work : Amazing progress in AI and Automation. Mckinsey, June.

Marzal, J. (2019). Revolusi Industri 4.0, Bagaimana Meresponnya. Humas Unja. https://www.unja.ac.id/2019/08/19/revolusi-industri-4-0-bagaimana-meresponnya/

Putra, N. E. (2019). Inilah yang Harus Disiapkan oleh Profesi Akuntan untuk Generasi Milenial Era Digital. Public Relation of Faculty of Economics \& Business. https://www.feb.ui.ac.id/blog/2019/09/19/inilah-yang-harus-disiapkan-oleh-profesiakuntan-untuk-generasi-milenial-era-digital/

Singh, S., \& Sukhvinder, S. (2010). Artificial Intelligence. International Journal of Computer Applications, 6(pp), 21-211. http://www.ijcaonline.org/volume6/number6/pxc3871413.pdf

Triatmaja, M. F., Acc, M., Acpa, A., Program, *, Akuntansi, S., Ekonomika, F., Bisnis, D., Muhammadiyah, U., \& Pekalongan, P. (2019). Seminar Nasional dan The 6th Call for Syariah Paper Universitas Muhammadiyah Surakarta Dampak Artificial Intelligence (AI) Pada Profesi Akuntan. Seminar Nasional Dan The 6th Call For Syariah Paper (SANCALL) 2019, 6(https://publikasiilmiah.ums.ac.id/handle/11617/11422), 1007-1019.

WEF. (2018). The Future of Jobs Report 2018. In Economic Development Quarterly (Vol. 31, Issue 2).

Wijayana, D. S. (2018). Benarkah Peran Akuntan Digantikan Oleh Teknologi (Informasi)? EB NEWS. https://feb.ugm.ac.id/en/research/lecturer-s-article/2886-benarkah-peran-akuntandigantikan-oleh-teknologi-informasi 